\title{
Prediction of Charpy Absorbed Energy of Steel for Welded Structure in Ductile-to-Brittle Fracture Transition Temperature Range*
}

\author{
by TAKASHIMA Yasuhito ** and MINAMI Fumiyoshi**
}

\begin{abstract}
Charpy impact tests are widely used for evaluating the notch toughness of materials and welded joints. Generally, the test results show a large statistical scatter in the ductile-to-brittle transition temperature range. Recent research found that the statistical distribution of the Charpy absorbed energy was characterized by a two-parameter Weibull distribution with a shape parameter of 2 under pure brittle fracture. In this study, a probabilistic model for evaluating notch toughness was applied. The Charpy impact test was conducted in the ductile-brittle transition temperature range, and the results showed a large statistical scatter. The Charpy absorbed energies at $1 \%, 50 \%$, and $99 \%$ fracture probability estimated by the maximum likelihood method with the two-parameter Weibull distribution and a shape parameter of 2 showed good agreement with the experimental data for pure brittle fracture. The temperature dependence of the scale parameter for the absorbed energy can be expressed as an exponential function. The absorbed energy predicted in the ductile-brittle transition temperature range by the probabilistic model showed good agreement with the experimental data under pure brittle fracture.
\end{abstract}

Key Words: Charpy impact test, Toughness, Statistical scatter, Brittle fracture, Structural steel

\section{Introduction}

Charpy impact tests are widely used for evaluating the notch toughness of materials. Generally, the test results show a large statistical scatter in the ductile-to-brittle transition temperature (DBTT) range. Many researchers have investigated estimation methods for the statistically scattered data of the DBTT assuming a normal distribution or a Weibull distribution [1-4].

For accurately estimation of the DBTT, understanding the statistic scatter is very important. Recent research $[3,4]$ found that the statistical distribution of the Charpy absorbed energy was characterized by a two-parameter Weibull distribution with a shape parameter of 2 under pure brittle fracture. This is due to the singularity approximately dominates the stress field near the Vnotch. In this study, a probabilistic model was applied for evaluating the notch toughness. The model was based on the weakest link theory and the master curve concept for the absorbed energy. The Charpy absorbed energy in the DBTT range for structural steel was estimated from test data measured in the lowershelf temperature range using the probabilistic model.

\section{Charpy impact test}

A $490 \mathrm{MPa}$ strength class steel for welded structure was used for the Charpy impact test. The thickness of the plate was $25 \mathrm{~mm}$. The chemical composition and the tensile properties of the steel at room temperature are listed in Tables 1 and 2, respectively.

* Received: 2019.11.21, Presented at Visual-JW or WSE 2019

** Member, Joining and Welding Research Institute Osaka University
Table 1 Chemical composition of the steel [mass \%]

\begin{tabular}{|c|c|c|c|c|}
\hline $\mathrm{C}$ & $\mathrm{Si}$ & $\mathrm{Mn}$ & $\mathrm{P}$ & $\mathrm{S}$ \\
\hline 0.15 & 0.27 & 1.51 & 0.01 & 0.002 \\
\hline
\end{tabular}

Table 2 Mechanical properties of the steel.

\begin{tabular}{|c|c|c|}
\hline $\begin{array}{c}\text { Yield stress } \\
{[\mathrm{MPa}]}\end{array}$ & $\begin{array}{c}\text { Tensile strength } \\
{[\mathrm{MPa}]}\end{array}$ & $\begin{array}{c}\text { Uniform } \\
\text { elongation }[\%]\end{array}$ \\
\hline 351 & 529 & 17 \\
\hline
\end{tabular}

The Charpy impact tests were conducted at several temperatures between $-100^{\circ} \mathrm{C}$ and $0^{\circ} \mathrm{C}$. A Charpy testing machine with a pendulum striker of $257 \mathrm{~N}$ and an arm length of $750 \mathrm{~mm}$, which produced an initial potential energy of $294 \mathrm{~J}$, was used. The Charpy specimens were cooled in liquid nitrogen atmosphere at the temperature below $-80^{\circ} \mathrm{C}$ or ethanol above $-70^{\circ} \mathrm{C}$. The specimens remained in the bath at the test temperature $\pm 2^{\circ} \mathrm{C}$ for a minimum of 10 minutes prior to testing.

The V-notched Charpy specimen is shown in Fig. 1. The Charpy specimen includes a standard V-notch with a depth of $2 \mathrm{~mm}$ and a root radius of $0.25 \mathrm{~mm}$. The Charpy specimen was extracted from one-quarter thick steel.

The absorbed energy $K_{\mathrm{V}}$ obtained from the Charpy impact tests

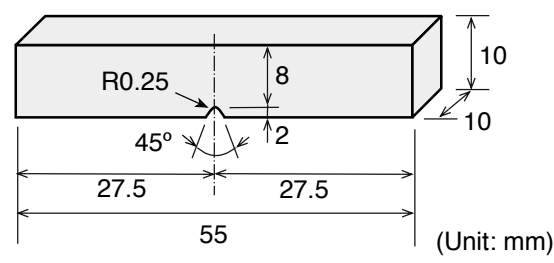

Fig. 1 Configuration of the V-notched Charpy specimen. 


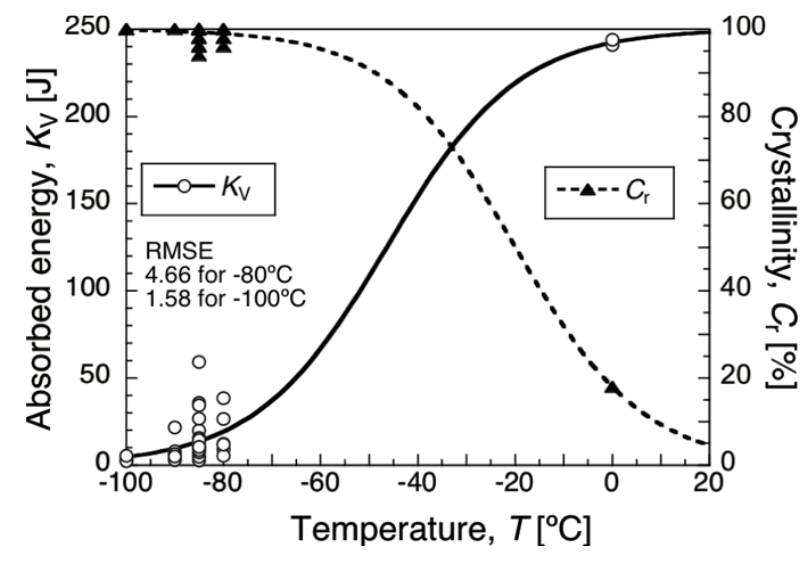

Fig. 2 Result of Charpy impact tests.

and the measured crystallinity $C_{\mathrm{r}}$ show a large statistical scatter. In this study, a fitting equation proposed by Oldfield [5] was employed for evaluating the regression curve. The fitting equation is expressed as follows.

$$
K_{\mathrm{v}}=\frac{\mathrm{USE}}{2}\left(1+\tanh \frac{T-\mathrm{DBTT}}{\mathrm{C}}\right)
$$

where the parameter USE is the upper shelf energy, and C is the range of the transition temperature. The DBTT determined by the least-square method with equation (1) was approximately $-45^{\circ} \mathrm{C}$, when USE and $\mathrm{C}$ were assumed to be $250 \mathrm{~J}$ and $25^{\circ} \mathrm{C}$, respectively. The root mean square error (RMSE) is shown in Fig. 2. The RMSE is above 1.0 at the lower shelf temperature.

\section{Stress fields in V-notched Charpy specimen}

The near V-notch dynamic stress/strain fields in the Charpy specimen were numerically analyzed using a three-dimensional finite element (FE) analysis. The three-dimensional FE code Abaqus/Standard Ver-6.12 was used in this study. The threedimensional mesh of the FE model is shown in Fig. 3. Because of the symmetry of the specimen, only one-quarter of it was modeled. Eight-node elements with eight Gaussian integration points were used in the FE analysis. The smallest element near the notch root had dimensions of $0.05 \mathrm{~mm} \times 0.05 \mathrm{~mm} \times 0.2 \mathrm{~mm}$.

The rate-dependent elastic-plastic material behavior of the specimen was considered in the FE analysis. The effect of the strain rate on the tensile properties was evaluated using the strain ratetemperature parameter $R$ proposed by Bennett and Sinclair [6]. The dependence of the tensile properties on temperature was evaluated using the empirical relation for low-carbon structural steels [7].

This analysis included the effect of the strain rate on the flow stress and the increase in temperature during impact loading. A fully coupled thermal stress analysis was conducted with the dynamic explicit analysis. Under the impact loading conditions,

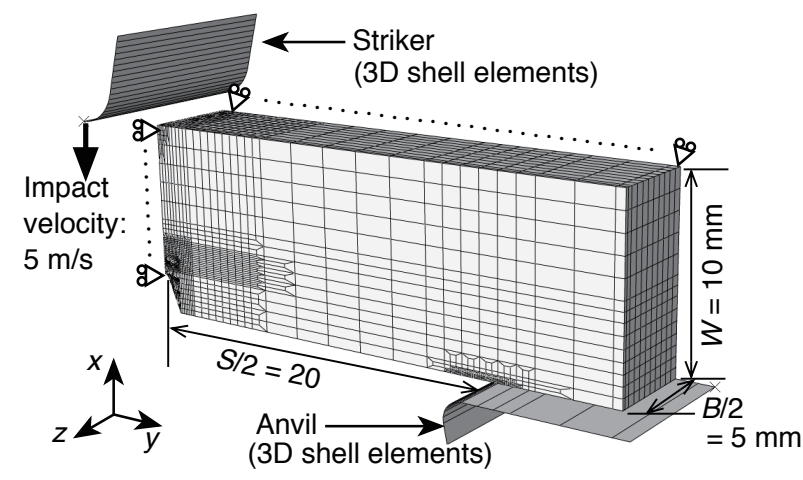

Fig. 3 Mesh division of the Charpy specimen (one-quarter model).

high-speed straining adiabatically generated heat. In this analysis, it was assumed that $90 \%$ of the plastic work was transferred to heat [8]. The thermal constants adopted in this analysis are listed in Table 3 .

Table 3 Thermal constants used for the FE analysis.

\begin{tabular}{|c|c|c|c|}
\hline $\begin{array}{c}\text { Specific } \\
\text { heat, } C \\
{[\mathrm{~J} / \mathrm{kg} \cdot \mathrm{K}]}\end{array}$ & $\begin{array}{c}\text { Density, } \rho \\
{\left[\mathrm{kg} / \mathrm{mm}^{3}\right]}\end{array}$ & $\begin{array}{c}\text { Thermal } \\
\text { conductivity, } \\
\lambda[\mathrm{W} / \mathrm{K} \cdot \mathrm{mm}]\end{array}$ & $\begin{array}{c}\text { Coefficient of linear } \\
\text { expansion, } \\
\alpha_{\mathrm{L}}[1 / \mathrm{K}]\end{array}$ \\
\hline $4.69 \times 10^{2}$ & $7.86 \times 10^{-6}$ & $5.18 \times 10^{-2}$ & $1.2 \times 10^{-5}$ \\
\hline
\end{tabular}

The inertial effect during impact loading was eliminated in this analysis. Nakamura et al. [9] proposed a transition time $t_{\mathrm{T}}$ that defined the point in the response after which the inertial effects diminished rapidly. The $t_{\mathrm{T}}$ was when the kinetic energy equaled the deformation energy of the specimen. They validated that a quasistatic analysis yielded acceptable accuracy after a time greater than $2 \times t_{\mathrm{T}}$. The $t_{\mathrm{T}}$ for the Charpy specimen was calculated as $2.5 \times 10^{-5}$ seconds using a dynamic explicit FE analysis [10]. In this study, we discussed the results of the FE analysis when the loading time exceeded $2 \times t_{\mathrm{T}}$ and the inertial effects could be neglected.

In a previous study [3], the notch opening stress $\sigma_{\mathrm{yy}}$ near the Vnotch in the linear elastic material was nearly inversely proportional to the square root of the distance $x$ from the notch root. Hence, $\sigma_{\mathrm{yy}}$ can be approximately written as equation (2).

$$
\frac{\sigma_{\mathrm{yy}}}{\sigma_{\mathrm{Y}}}=\frac{Y P S}{\sigma_{\mathrm{Y}} B W^{3 / 2} \sqrt{2 \pi x}}
$$

The parameter $Y$ is a constant. The parameter $P$ is the applied load, and $B$ and $W$ are the specimen thickness and width, respectively. The parameter $\sigma_{Y}$ is the yield stress. Therefore, the stress distribution can be expressed as a function of the nondimensional distance $x /\left\{P S /\left(\sigma_{\mathrm{Y}} B W^{3 / 2}\right)\right\}^{2}$.

Fig. 4 shows the distributions of the notch opening stress as a function of the non-dimensional distance. The yield stress under static loading condition at each temperature was employed as $\sigma_{\mathrm{Y}}$ in equation (2). The stress distribution indicated that the $x^{-1 / 2}$ 


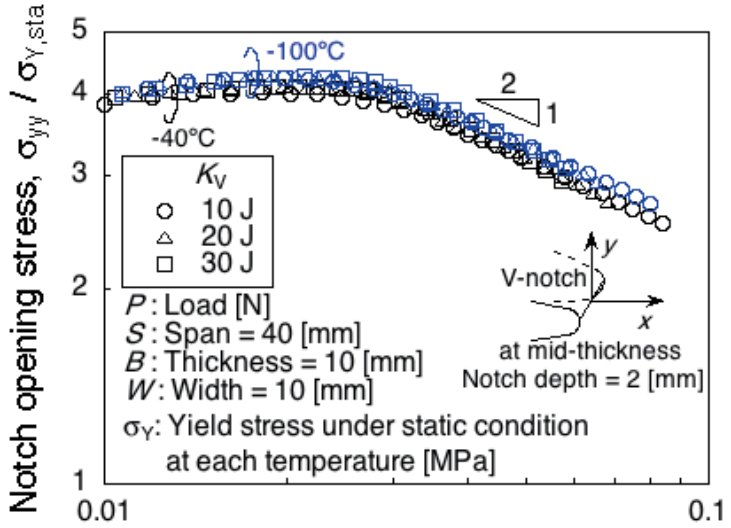

Distance from notch root, $x /\left\{P S /\left(\sigma_{Y} B W^{3 / 2}\right)\right\}^{2}$

Fig. 4 Opening stress ahead of the V-notch in the Charpy specimen.

singularity approximately dominated the stress field near the Vnotch at not only $-100^{\circ} \mathrm{C}$ for the lower-shelf temperature but also $-40^{\circ} \mathrm{C}$ for the DBTT. The peak value of the stress distribution was approximately four times that of the yield stress at each temperature.

\section{Probabilistic distribution of Charpy absorbed energy}

When the $x^{-1 / 2}$ singularity approximately dominated the stress field, the statistical distribution of the Charpy absorbed energy could be characterized by a two-parameter Weibull distribution with a shape parameter of 2 . In this section, the statistical scatter of $K_{\mathrm{V}}$ in the lower-shelf temperature range of $-100^{\circ} \mathrm{C}$ to $-80^{\circ} \mathrm{C}$ is discussed. The $K_{\mathrm{V}}$ measured at each temperature was plotted in a Weibull paper, as shown in Fig. 5. The cumulative frequency was evaluated by the median rank equation. The slope of the plotted data in the Weibull paper was approximately 2 at each temperature. In the lower-shelf temperature range of $-100^{\circ} \mathrm{C}$ to $-80^{\circ} \mathrm{C}$, the $K_{\mathrm{V}}$ corresponding to the same $F$ increased with an increase in

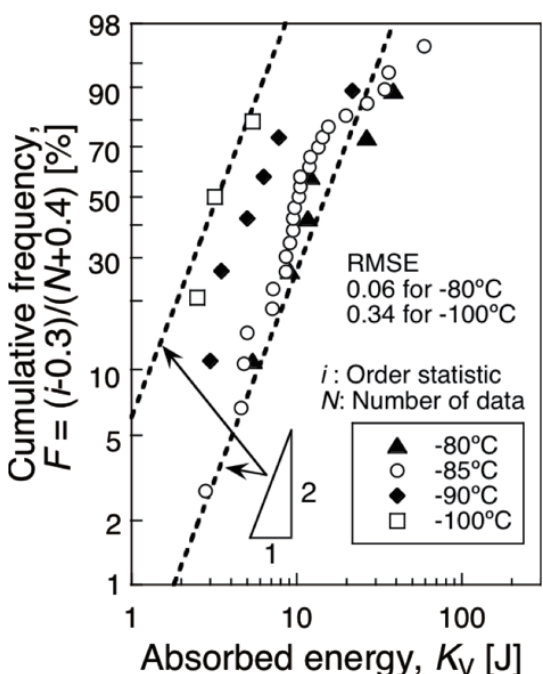

Fig. 5 Weibull probability distribution of the Charpy absorbed energy at the lower-shelf temperature. temperature. The value of RMSE shown in Fig. 5 is fine.

The authors found similar results at a temperature below the DBTT for many structural steels and welds [10]. These results indicated that the statistical distribution of the Charpy absorbed energy was characterized by a two-parameter Weibull distribution with a shape parameter of 2 under pure brittle fracture.

In this study, a probabilistic model for evaluating notch toughness was applied. The probabilistic model assumed the statistical scatter of $K_{\mathrm{V}}$ to be a two-parameter Weibull distribution with a shape parameter of 2 . This model estimated the Weibull scale parameter from the few data points at each temperature in the lower-shelf range. Khalili and Kromp [11] investigated the Weibull parameters using a Monte Carlo simulation and reported that a minimum of 30 samples was required for a good characterization of the strength of a brittle material when the Weibull shape parameter was unknown. Conversely, when the Weibull shape parameter was known, the Weibull scale parameter could be estimated more accurately from a few samples. Harter and Moore [12] reported that the maximum likelihood estimation error of the scale parameter with a shape parameter of 2 was lower than $2 \%$ when using more than 6 samples. In this study, the sample sizes were greater than 6 except at $-100^{\circ} \mathrm{C}$. When the sample size was 3 , the error of the maximum likelihood estimator of the scale parameter with a shape parameter of 2 was $4 \%$ [12]. The Weibull scale parameter $K_{\mathrm{V} 0}\left(=K_{\mathrm{V}}(F=63 \%)\right)$ at each temperature was estimated by the maximum likelihood method. When the Weibull shape parameter is 2 , the Weibull scale parameter is given by equation (3)

$$
K_{V 0}=\left(\sum_{i=1}^{N} K_{V} / N\right)^{2}
$$

The parameter $N$ is the number of data points, and $i$ is the order statistic. The estimated $K_{\mathrm{V}}(F=63 \%)$ at each temperature using equation (3) showed a temperature dependence. The master curve concept is widely used for evaluating temperature dependence of brittle fracture toughness $[13,14]$. In this study, the master curve of

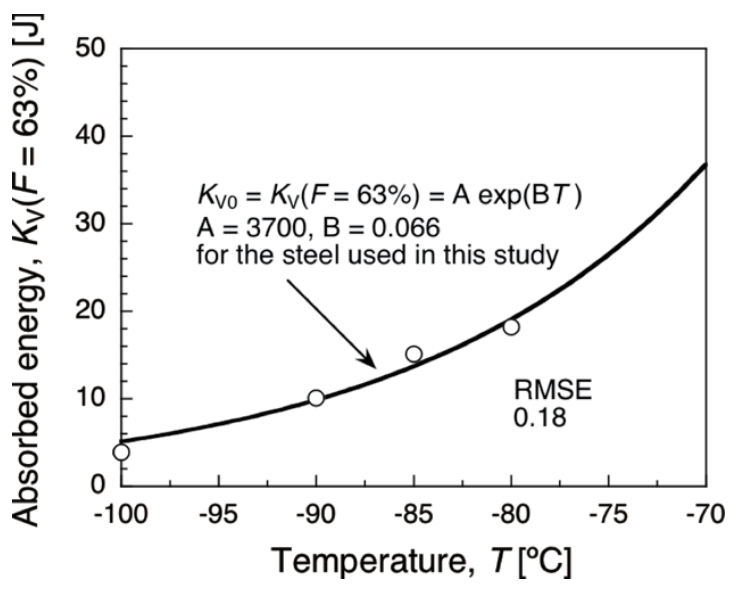

Fig. 6 Temperature dependence of the Weibull scale parameter for the $K_{\mathrm{V}}$. 
notch toughness was discussed. The temperature dependence of $K_{\mathrm{V} 0}$ in the lower-shelf temperature range was plotted in Fig. 6. The regression curve for $K_{\mathrm{V} 0}$ employed in this study is expressed as follows.

$$
K_{\mathrm{v} 0}=K_{\mathrm{V}}(F=63 \%)=3700 \exp (0.066 T)
$$

The determined regression curve for the steel is shown in Fig. 6 . The RMSE was 0.18 for the regression. This indicated that the determined regression curve gave fine prediction.

\section{Prediction of Charpy absorbed energy}

The Charpy absorbed energies in the DBTT range of $-70^{\circ} \mathrm{C}$ to $-40^{\circ} \mathrm{C}$ were predicted from the test data measured in the lowershelf temperature range of $-100^{\circ} \mathrm{C}$ to $-80^{\circ} \mathrm{C}$ using the probabilistic model.

The temperature dependence of $K_{\mathrm{V}}(F=63 \%)$ was evaluated using the regression curve shown in Fig. 6 . The value of the Charpy absorbed energy corresponding to several fracture probabilities $K_{\mathrm{V}}(F)$ was determined by the following equation.

$$
K_{\mathrm{V}}(F)=K_{\mathrm{v} 0} \ln \left(\frac{1}{1-F}\right)^{1 / 2}
$$

Fig. 7 shows the predicted distribution of $K_{\mathrm{V}}$ at $-70^{\circ} \mathrm{C}$. The predicted $K_{\mathrm{V}}$ showed an adequate agreement with the experimental data. The RMSE for the prediction was lower than 1.0 and this means fine prediction. The test results at $-70^{\circ} \mathrm{C}$ shows a large statistical scatter. The scatter corresponded to the predicted distribution.

Fig. 8 shows the predicted $K_{\mathrm{V}}$ from the probabilistic model using equation (6) and measured by the Charpy impact test. The predicted $K_{\mathrm{V}}$ agreed well with the measured $K_{\mathrm{V}}$, except for the ductile-cracking results at the $\mathrm{V}$-notch prior to brittle fracture. The

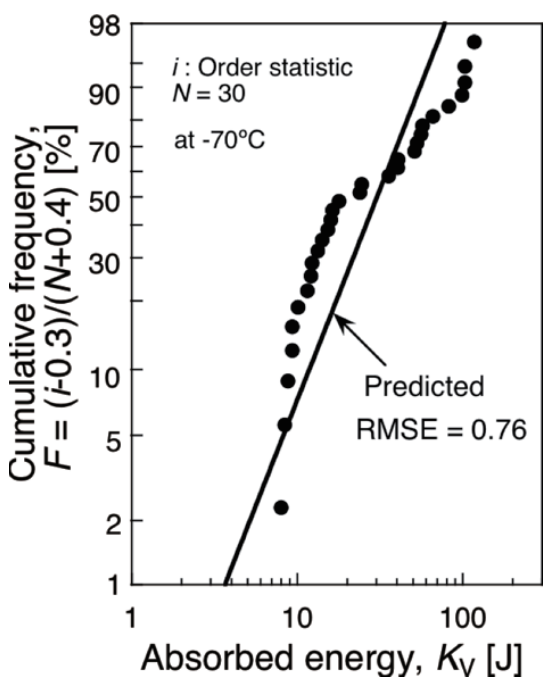

Fig. 7 Comparison between the Weibull probability distribution of the $K_{\mathrm{V}}$ predicted and measured at $-70^{\circ} \mathrm{C}$.

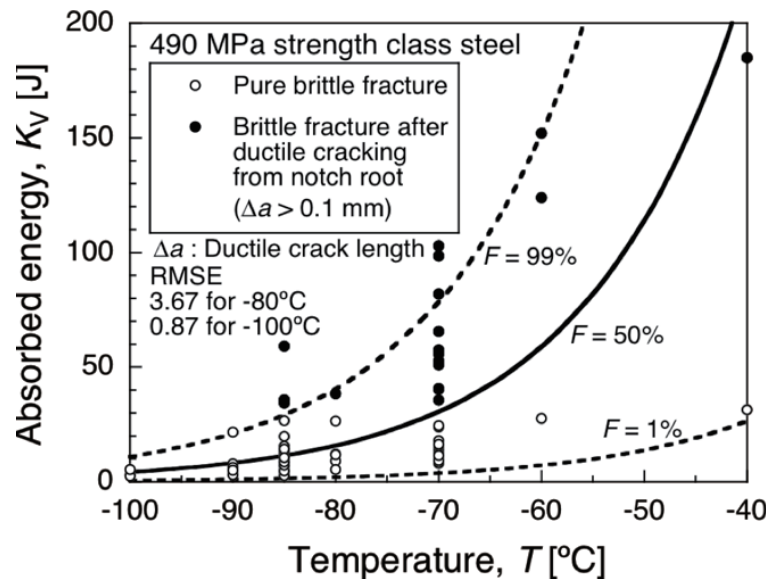

Fig. 8 Comparison between the Charpy absorbed energy predicted by the probabilistic model and measured by the Charpy impact test.

RMSE shown in Fig. 8 was smaller than that shown in Fig. 2. This indicated that the prediction was good by using exponential function. This indicated that $K_{\mathrm{V}}$ in the DBTT range could be estimated from the test data measured in the lower-shelf temperature range using the probabilistic model under pure brittle fracture.

\section{Conclusions}

In this study, the statistical scatter of the Charpy absorbed energy was investigated using a low-carbon steel for welded structure. The statistical distribution of the Charpy absorbed energy was characterized by a two-parameter Weibull distribution with a shape parameter of 2 at each temperature in the lower-shelf range.

The probabilistic model for evaluating notch toughness was applied. In the temperature range below the DBTT, the scale parameter of the absorbed energy was estimated by the maximum likelihood method with the shape parameter of 2 at each temperature. The temperature dependence of the scale parameter for the absorbed energy can be expressed as an exponential function. The absorbed energy in the DBTT range predicted by the probabilistic model showed good agreement with the experimental data under pure brittle fracture.

\section{Acknowledgements}

The authors of this work would like to express their gratitude to the Fundamental Research Developing Association for Shipbuilding and Offshore (REDAS) in Japan for financial support of this study.

\section{Reference}

1) M.T. Todinov: Estimating the parameters of the impact energy variation in the ductile/brittle transition region from complete and sparse data, Comput. Mater. Sci., 21 (2001), 111-123. 
2) I. Orynyak, M. Zarazovskii, A. Bogdan: Determination of the transition temperature scatter using the Charpy data scatter, ASME Pressure Vessels and Piping Conference, Paris (2013), PVP201397697.

3) Y. Takashima, M. Ohata, F. Minami: Analysis of statistical scatter in Charpy impact toughness, Mater. Sci. Forum 783-786 (2014), 2394 2399.

4) S. Matsuda, M. Takahashi: Probabilistic model for brittle fracture and statistical characteristic of absorbed energy in Charpy impact test, J. Jpn. Inst Met. Mater. 82 (2018) 102-107. (in Japanese)

5) W. Oldfield: Fitting curves to toughness data, J. Test. Eval. 7 (1979) 326-333.

6) P.E. Bennett, G.M. Sinclair: Parameter representation of lowtemperature yield behavior of body-centered cubic transition metals, Trans. Am. Soc. Mech. Eng. 88 (1966) 518-524.

7) Japan Welding Engineering Society, BE-committee research report, 1975. (in Japanese)
8) G.I. Taylor, H. Quinney: The latent energy remaining in a metal after cold working, Proc. R. Soc. Lond. A. 143 (1934) 307-326.

9) T. Nakamura, C.F. Shih, L.B. Freund: Analysis of a dynamically loaded three-point-bend ductile fracture specimen, Eng. Fract. Mech. 25 (1986) 323-339.

10) Y. Takashima, T. Handa, F. Minami: Three-dimensional dynamic explicit finite element analysis of Charpy impact test, Mater. Sci. Forum. 879 (2017) 1905-1910.

11) A. Khalili, K. Kromp: Statistical properties of Weibull estimators, J. Mater. Sci. 26 (1991) 6741-6752.

12) H.L. Harter, A.H. Moore: Point and interval estimators, based on $m$ order statistics, for the scale parameter of a Weibull population with known shape parameter, Technometrics 7-3 (1965), 405-422.

13) K. Wallin: The master curve method: A new concept for brittle fracture, Int. J. Mater. Prod. Technol. 14-2/3/4 (1999) ,342-354.

14) K. Wallin, A simple theoretical Charpy-V $K_{I c}$ correlation for irradiation embrittlement, ASME Pressure Vessels and Piping Conference, 170 (1989), 93-100. 